\title{
Scaling up prevention and control of noncommunicable diseases in the WHO Eastern Mediterranean Region
}

Heba Fouad ${ }^{1}$, Nisreen Abdel Latif ${ }^{1}$, Rachel A Ingram ${ }^{1}$ and Asmus Hammerich ${ }^{1}$

${ }^{1}$ WHO Regional Office for the Eastern Mediterranean, Cairo, Egypt (Correspondence to: Heba Fouad: fouadh@who.int)

\begin{abstract}
Surveillance is an essential component in the campaign to prevent and control noncommunicable diseases (NCDs), both globally and in the Eastern Mediterranean Region (EMR). In order to address the increasing burden from these diseases, countries must first evaluate their own systems and see what steps need to be taken to improve preparedness. Therefore, the WHO Regional Office for the Eastern Mediterranean in Cairo, Egypt, conducts country capacity surveys on a regular basis to compare each Member State's NCD provision to the Framework for Action to implement the UN Political Declaration (2011). Ten progress indicators cover governance and planning, reducing risk factors and healthcare provision. Each one is scored for whether a country is fully, partially or not achieving this goal. This review focuses on comparing the Progress Monitor reports for the 22 EMR countries in 2015 and 2017. While the criteria used to assess some of the indicators have been updated over this period, many categories still show strong improvements. However, others still require extensive work if countries are to meet the sustainable development goal of reducing by $25 \%$ the number of premature deaths from NCDs by the year 2025.
\end{abstract}

Citation: Fouad H, Abdel Latif N, Ingram R A, Hammerich A. Scaling up prevention and control of noncommunicable diseases in the WHO Eastern Mediterranean Region. East Mediterr Health J. 2018;24(1):52-62. https://doi.org/10.26719/2018.24.1.52

Received: 11/01/18; accepted: 05/03/18

Copyright (c) World Health Organization (WHO) 2018. Some rights reserved. This work is available under the CC BY-NC-SA 3.o IGO license (https:// creativecommons.org/licenses/by-nc-sa/3.o/igo).

\section{The importance of measuring national progress on prevention and control of noncommunicable diseases}

Noncommunicable diseases (NCDs) are now the world's biggest killers (1) and a leading cause of death and disability in the WHO Eastern Mediterranean Region (EMR) (2). The four main NCDs are cardiovascular disease (including heart attacks and stroke), diabetes, cancer and chronic respiratory disease (such as chronic obstructed pulmonary disease and asthma) (1-3). Over half of deaths caused by NCDs are premature, occurring before the age of 70 (2). Such data show that NCDs affect economically productive individuals, which impoverishes families while also placing a considerable burden on health systems and national economies. This can subsequently stifle the potential for socioeconomic development (2-4). In the WHO Eastern Mediterranean Region, NCDs are responsible for around $60 \%$ of all deaths, a total of 1.7 million a year $(2,3)$. This figure is expected to increase to more than 3.8 million by 2030 unless major steps are taken to combat this rise (3). The Region also has some of the highest global rates of NCD-related risk factors; namely physical inactivity, tobacco consumption, and high salt, sugar and fat intake (5). Many of the premature deaths and disability caused by NCDs have the potential to be prevented by addressing these key common risk-factors through lifestyle changes and "best buy" interventions. However, achieving this reduction will require sound and committed national, regional and international efforts.

An essential step in tackling the burden of NCDs, both globally and in the EMR, is to first understand and assess the capacity of individual countries in prevention and control of these diseases. To this end, WHO conducts country capacity surveys on a regular basis since 2000, with the two most recent Progress Monitor publications released in 2015 and September $2017(6,7)$. This process of measuring and updating countries periodically on progress aims to identify their individual strengths and weaknesses. The results allow countries to devise distinct plans to scale up implementation of NCD control policies and actions by strengthening their capacities and human resources.

This review highlights the progress made in the prevention and control of NCDs among the EMRMember States. Specifically it looks at commitments made by countries to reverse this epidemic, compares progress made by countries between 2015 and 2017 to meet these targets, and discusses recommended action and ways forward for countries to stay true to their commitments.

\section{Commitments made by countries to reverse the NCD epidemic}

In 2011, a high-level meeting of the United Nations General Assembly was held to discuss the prevention and control of NCDs. The outcome of this meeting was a political declaration where countries made commitments to take specific actions to address the burden associated with NCDs (8). This was endorsed by EMR Member States in the form of the Regional Framework for Action in 2012 (9). The Regional Framework provides strategic interventions and indicators to assess country progress in the four following areas: governance; prevention and 
reduction of risk factors; surveillance, monitoring and evaluation; and health care (Figure 1).

\section{Process and tools for measuring national progress on prevention and control of NCDs}

Globally, WHO measures national progress on the prevention and control of NCDs using 10 progress monitoring indicators (7). In the Eastern Mediterranean Regional Framework, these indicators are divided into four areas: governance; prevention and reduction of risk factors; surveillance, monitoring and evaluation; and health care (9). In 2014, the WHO Regional Office for the Eastern Mediterranean, Cairo, Egypt (EMRO), developed country profiles that utilize a "traffic light" system. This allows EMRO to update countries on progress made in the prevention and control of NCDs on a regular basis. The major source of information in determining achievement of the indicators is the NCD country capacity survey (NCD CCS) carried out by EMRO at regular intervals. Additional data for some sections is also provided by the WHO Global Report on the Tobacco Epidemic and by the Global Survey on Alcohol and Health.

In May 2013, the World Health Assembly endorsed the WHO Global Action Plan for the Prevention and Control of NCDs 2013-2020 (10). The Global Action Plan provides Member States, international partners and WHO with a road map and menu of policy options. When implemented collectively between 2013 and 2020, this will contribute to progress on 9 global NCD targets to be attained in 2025, including a $25 \%$ relative reduction in premature mortality from NCDs by 2025 (10). WHO's global monitoring framework on NCDs started tracking implementation of the Global Action Plan through monitoring and reporting on the attainment of the 9 global targets against a baseline in 2010 (11). The 9 voluntary global targets (Figure 2) address key NCD risk factors, including tobacco use, salt intake, physical inactivity, high blood pressure and harmful use of alcohol. The WHO Global Action Plan (2013-2020) in its Appendix 3 provides a total of 14 "best buys" or cost-effective, high-impact interventions out of 81 recommended interventions by WHO. The original best buys included banning all forms of tobacco advertising, replacing trans fats with polyunsaturated fats, restricting or banning alcohol advertising, preventing heart attacks and strokes, promoting breastfeeding, implementing public awareness programmes on diet and physical activity, and preventing cervical cancer through screening among other policy options (10). In May 2017 an update to Appendix 3 was endorsed by the Seventieth World Health Assembly. It now reflects the latest WHO recommendations on evidence-based cost-effective strategies, comprising a total of 88 interventions, out of which there are a total of 16 "Best buys" - those considered as most effective and feasible for implementation (12).

\begin{tabular}{|c|c|c|}
\hline 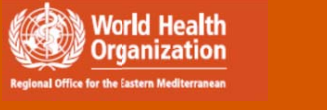 & \multicolumn{2}{|c|}{$\begin{array}{l}\text { Framework for action to implement the United Nations Political Declaration on } \\
\text { Noncommunicable Diseases, including indicators to assess country progress by } 2018 \\
\text { Updated October 2015, based on resolutions EM/RC59/R.2 \& EM/RC60/R.4 }\end{array}$} \\
\hline Commitments & Strategic interventions & Progress indicators \\
\hline $\begin{array}{l}\text { In the area of } \\
\text { governance }\end{array}$ & $\begin{array}{l}\text { Each country is expected to: } \\
\text { - Integrate noncommunicable diseases into national policies and development plans } \\
\text { - Establish a multisectoral strategy/plan and a set of national targets and indicators for } 2025 \\
\text { based on national situation and WHO guidance } \\
\text { - Increase budgetary allocations for noncommunicable diseases prevention and control } \\
\text { including through innovative financing mechanisms such as taxation of tobacco, alcohol and } \\
\text { other unhealthy products } \\
\text { - Periodically assess national capacity for prevention and control of noncommunicable } \\
\text { diseases using WHO tools }\end{array}$ & $\begin{array}{l}\text { Country has: } \\
\text { - An operational multisectoral national strategy/action plan that integrates the major } \\
\text { NCDs and their shared risk factors } \\
\text { - Set time-bound national targets and indicators based on WHO guidance }\end{array}$ \\
\hline Commitments & Strategic interventions & Progress indicators \\
\hline $\begin{array}{l}\text { In the area of } \\
\text { prevention and } \\
\text { reduction of } \\
\text { risk factors }\end{array}$ & $\begin{array}{l}\text { Each country is expected to: } \\
\text { - Accelerate implementation of the WHO Framework Convention on Tobacco Control (WHO } \\
\text { FCTC) and ratify Protocol to Eliminate Illicit Trade in Tobacco Products } \\
\text { - Ensure healthy nutrition in early life and childhood including breastfeeding promotion and } \\
\text { regulating marketing of foods and non-alcoholic beverages to children } \\
\text { - Reduce average population salt intake in line with WHO recommendations } \\
\text { - Virtually eliminate transfat intake and reduce intake of saturated fatty acids } \\
\text { - Promote physical activity through a life-course approach } \\
\text { - Implement the best buys to reduce the harmful use of alcohol }\end{array}$ & $\begin{array}{l}\text { Country is implementing: } \\
\text { - Four demand-reduction measures of the WHO FCTC at the highest level of achievement } \\
\text { - Four measures to reduce unhealthy diet } \\
\text { - At least one recent national public awareness programme on diet and/or physical } \\
\text { activity } \\
\text { - As appropriate, according to national circumstances, three measures to reduce the } \\
\text { harmful use of alcohol, in line with the WHO global strategy to reduce the harmful use } \\
\text { of alcohol }\end{array}$ \\
\hline Commitments & Strategic interventions & Progress indicators \\
\hline $\begin{array}{l}\text { In the area of } \\
\text { surveillance, } \\
\text { monitoring and } \\
\text { evaluation }\end{array}$ & $\begin{array}{l}\text { Each country is expected to: } \\
\text { - Implement/strengthen the WHO surveillance framework that monitors mortality and } \\
\text { morbidity, risk factors and determinants, and health system capacity and response } \\
\text { - Integrate the three components of the surveillance framework into the national health } \\
\text { information system } \\
\text { - Strengthen human resources and institutional capacity for surveillance, monitoring and } \\
\text { evaluation }\end{array}$ & $\begin{array}{l}\text { Country has: } \\
\text { - A functioning system for generating reliable cause-specific mortality data on a routine } \\
\text { basis } \\
\text { - A STEPS survey or a comprehensive health examination survey every } 5 \text { years }\end{array}$ \\
\hline Commitments & Strategic interventions & Progress indicators \\
\hline $\begin{array}{l}\text { In the area of } \\
\text { health care }\end{array}$ & $\begin{array}{l}\text { Each country is expected to: } \\
\text { - Implement the best buys in health care } \\
\text { - Improve access to early detection and management of major noncommunicable diseases } \\
\text { and risk factors by including them in the essential primary health care package } \\
\text { - Improve access to safe, affordable and quality essential medicines and technologies for } \\
\text { major noncommunicable diseases } \\
\text { - Improve access to essential palliative care services }\end{array}$ & $\begin{array}{l}\text { Country has: } \\
\text { - Evidence-based national guidelines/protocols/standards for management of major } \\
\text { noncommunicable diseases through a primary care approach, recognized/approved by } \\
\text { the government or competent authority } \\
\text { - Provision of drug therapy, including glycaemic control, and counselling for eligible } \\
\text { persons at high risk to prevent heart attacks and strokes, with an emphasis on the } \\
\text { primary care level }\end{array}$ \\
\hline OWorld Health & tanization & $\begin{array}{ll}\text { WHO-EM/NCD/121/E } \\
\end{array}$ \\
\hline
\end{tabular}

Figure 1 Framework for Action to Implement the UN Political Declaration, developed by the WHO Eastern Mediterranean Regional Office and endorsed by Member States (9) 


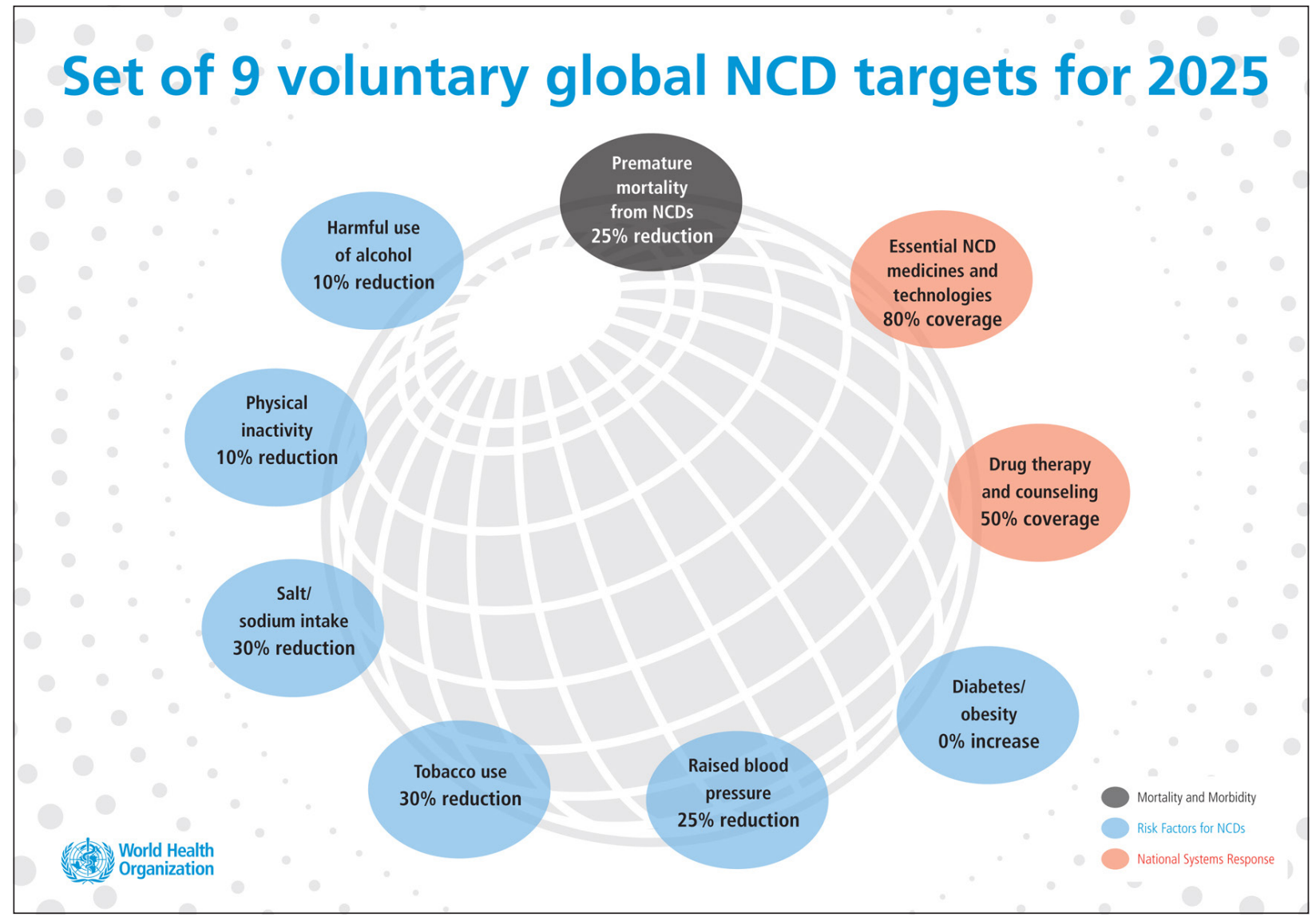

Figure 2 The nine voluntary global targets to be attained by 2025 , including a $25 \%$ relative reduction in premature mortality from NCDs by 2025

In 2015, WHO Member States set their national targets and began measuring their progress on the 2010 baseline reported in the WHO Global Status Report on Noncommunicable Diseases 2014 (13). In 2014, an outcome document was produced by the UN High-level Meeting of the General Assembly on the Prevention and Control of Non-communicable Diseases, where countries agreed to achieve four time-bound commitments in 2015 and 2016 (14) (Table 1). As a result, WHO developed a set of 10 progress indicators to facilitate monitoring these commitments and updating countries on progress made in implementation (15). These indicators were further updated in September 2017 to ensure consistency with the updated WHO "best buys" (16). They were then used in a WHO report submitted to the UN General Assembly at the end of 2017 in preparation for a comprehensive review of progress by the General Assembly in 2018. The results of the 2017 country capacity survey have also been visualized into the traffic lights system, and will inform progress made in the Region based on these 10 progress indicators.

\section{Key findings of the WHO NCD Country Capacity Survey: comparison between 2015 and 2017}

The WHO NCD Country Capacity Survey (NCD-CCS) collects information using a structured evaluation of the national efforts to prevent and control NCDs. Categories are aligned with the 10 progress monitoring indicators that are also used for other publications with WHO. Additional data is obtained from WHO Global reports on the tobacco epidemic and Alcohol and health. The NCD-CCS was conducted in 2000, 2005, 2010, 2013, 2015 and 2017. The Regional Office visualized the results of the survey using the "traffic light" system to facilitate reporting to countries on progress made thus far in the prevention and control of NCDs, identifying areas where implementation is lagging, and making recommendations on moving forward to meet global and regional commitments.

This review focuses on comparing the 10 progress indicators that were evaluated in the 22 EMR Member States in 2015 and 2017 (Table 1). One Member State did not complete the NCD-CCS in 2015 but was included in 2017. While indicators $1,4,5 \mathrm{~b}, 5 \mathrm{~d}, 6 \mathrm{a}-\mathrm{c}, 7 \mathrm{~b}, 7 \mathrm{c}$, and 10 remained the same in both surveys, some refinements were made to other categories including rewording and the addition of extra sub-indicators. The criteria used to assess attainment of each indicator were also altered in some cases in the 2017 NCD-CCS when compared to 2015 to include additional validation. These methodological disparities lead to some limitations in comparing data between the two years. However, this analysis still provides a useful measure of overall progress in the region over the recent period. 
Table 1 Time-bound commitments included in the 2014 Outcome Document and resulting indicators used for the Progress Monitor of 2017 (16).

Time-bound commitments included in the 2014 Outcome Document

Consider setting national targets for 2025 and process indicators based on national situations, taking into account the nine voluntary global targets for NCDs, building on guidance provided by WHO, to focus on efforts to address the impacts of NCDs and to assess the progress made in the prevention and control of NCDs and their risk factors and determinants.

Consider developing or strengthening national multisectoral policies and plans to achieve the national targets by 2025 , taking into account the WHO Global NCD Action Plan 2013-2020.

As appropriate, reduce risk factors for NCDs and underlying social determinants through the implementation of interventions and policy options to create health promoting environments, building on guidance set out in Appendix 3 to the WHO Global NCD Action Plan 2013-2020.
Ten indicators used by the Director-General to report, by the end of 2017, to the United Nations General Assembly on the progress achieved in the implementation of the time-bound commitments included in the 2014 Outcome Document

1. Member State has set time-bound national targets based on WHO guidance.

2. Member State has a functioning system for generating reliable cause-specific mortality data on a routine basis.

3. Member State has a STEPS survey or a comprehensive health examination survey every 5 years.

4. Member State has an operational multisectoral national strategy/ action plan that integrates the major NCDs and their shared risk factors.

5. Member State has implemented the following four demandreduction measures of the WHO FCTC at the highest level of achievement:

a. reduce affordability by increasing excise taxes and prices on tobacco products;

b. Eliminate exposure to second-hand tobacco smoke in all indoor workplaces, public places and public transport;

c. Implement plain/standardized packaging and/or large graphic health warnings on all tobacco packages;

d. Enact and enforce comprehensive bans on tobacco advertising, promotion and sponsorship;

e. Implement effective mass media campaigns that educate the public about the harm of smoking/tobacco use and second-hand tobacco smoke.

6. Member State has implemented, as appropriate according to national circumstances, the following three measures to reduce the harmful use of alcohol as per the WHO Global Strategy to Reduce the Harmful Use of Alcohol:

a. Enact and enforce restrictions on the physical availability of retailed alcohol (via reduced hours of sale);

b. Enact and enforce bans or comprehensive restrictions on exposure to alcohol advertising (across multiple types of media);

c. Increase excise taxes on alcoholic beverages.

7. Member State has implemented the following four measures to reduce unhealthy diets:

a. adopt national policies to reduce population salt/sodium consumption;

b. adopt national policies that limit saturated fatty acids and virtually eliminate industrially produced trans fatty acids in the food supply;

c. WHO set of recommendations on marketing of foods and nonalcoholic beverages to children;

d. legislation/regulations fully implementing the International Code of Marketing of Breast-milk Substitutes.

8. Member State has implemented at least one recent national public awareness programme and motivational communication for physical activity behavioural change.

As appropriate, strengthen and orient health systems to address the prevention and control of NCDs and the underlying social determinants through people-centred primary health care and universal health coverage throughout the life cycle, building on guidance set out in Appendix 3 to the WHO Global NCD Action Plan 2013-2020.
9. Member State has evidence-based national guidelines/protocols/ standards for the management of major NCDs through a primary care approach, recognized/approved by government or competent authorities.

10. Member State has provision of drug therapy, including glycemic control, and counselling for eligible persons at high risk to prevent heart attacks and strokes, with emphasis on the primary care level. 
One area of notable improvement was in the governance of NCDs. Between 2015 and 2017, the number of Member States that had set time-bound national targets based on WHO guidance increased from only 3 (14\%) out of 22 countries to 12 (55\%) (Figure 3). In 2015, only one country in the Region had an operational multisectoral national strategy/action plan that integrates the major NCDs and their shared risk factors. By 2017, eight Member States (36\%) had fully achieved this indicator. A further five Member States had partially achieved it and thus, showed their firm commitment to implementing this action in the future.

By comparison, the national surveillance of NCDs still requires development. Currently no EMR Member States have fulfilled the criteria towards having a fully functioning system for routinely generating reliable cause-specific data, although more than half (14) are working towards this target. The number conducting STEPS surveys at least every 5 years only improved slightly from two to three countries between 2015 and 2017. Clearly this is an area on which to focus in the future.

Prevention of NCDs is focused upon through reduction of the four main contributing risk factors. The work of the WHO Framework Convention for Tobacco
Control (FCTC) is assessed with a number of indicators in the Progress Monitor (Figure 3). Member States' progress in this area was mixed; on some indicators there was no improvement in the number fully achieving the target. However, encouraging increases were seen in the number of Member States comprehensively banning tobacco advertising, promotion and sponsorship, from six (27\%) in 2015 to nine countries (41\%) in 2017 . A newly introduced indicator for 2017 required countries to implement mass media campaigns to educate the public about the comprehensive health risks of tobacco. By the time of the 2017 survey, three out of 22 countries in the Region (14\%) had fully achieved this target (Figure 3) and another six had partially achieved its implementation.

Nearly half of the Member States have implemented alcohol harm reduction measures to reduce the availability and promotion of alcohol and increase its cost as per the WHO Global Strategy. Eleven (50\%) countries enacted and enforced restrictions on the physical availability of retailed alcohol, 12 (55\%) enacted and enforced bans or comprehensive restrictions on exposure to alcohol advertising (across multiple types of media) and nine countries (41\%) increased excise taxes on alcoholic beverages (Figure 3).

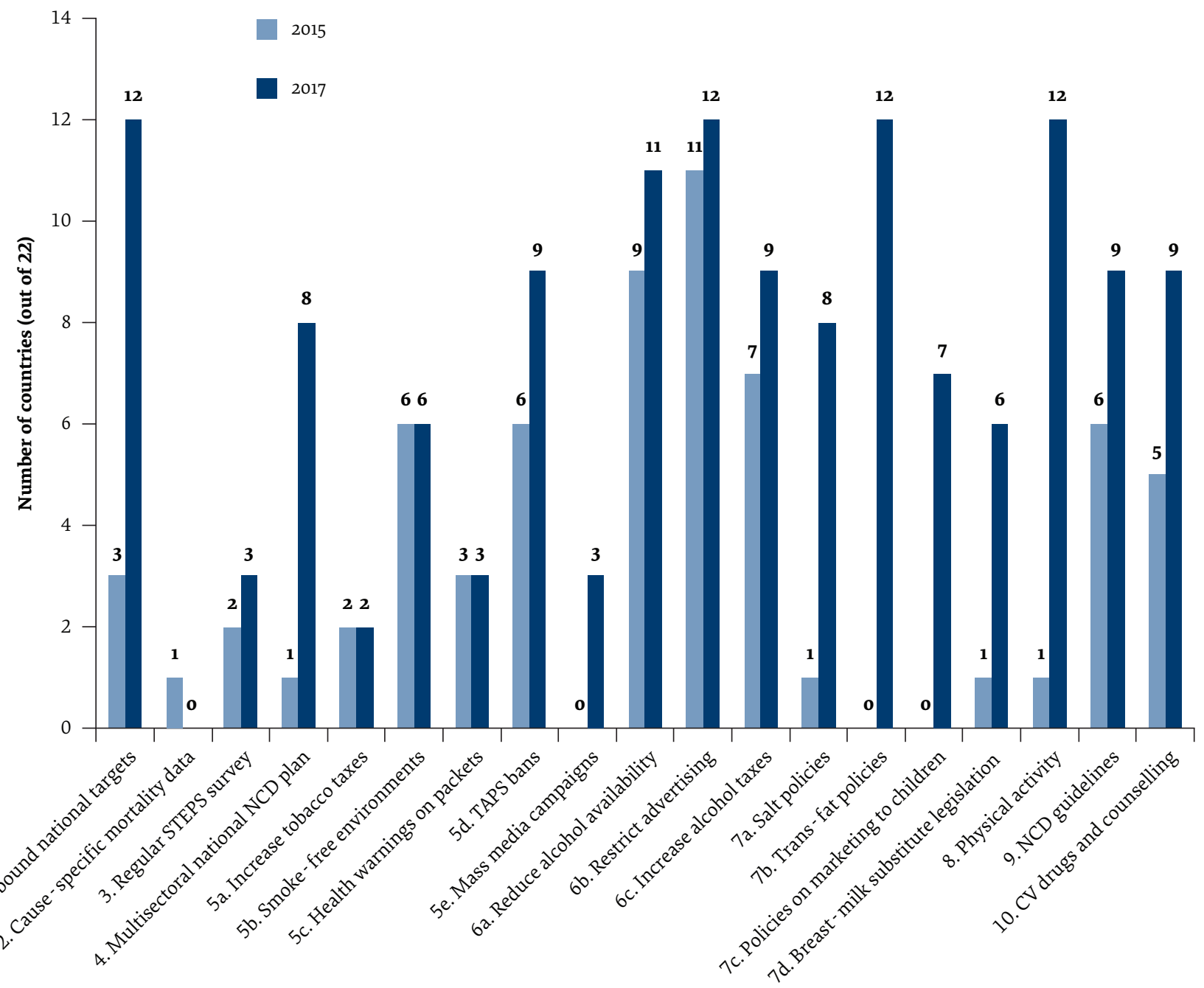

Figure 3 Regional progress on 10 indicators between 2015 and 2017 
The progress monitor assesses the implementation of four measures to reduce unhealthy diets. In 2017, eight countries adopted national policies to reduce population salt/sodium consumption. Twelve $(55 \%)$ out the 22 Member States adopted national policies that limit saturated fatty acids and virtually eliminate industrially produced trans-fatty acids in the food supply. Nearly one third of Member States (7/22) reported implementing policies to reduce marketing of foods and non-alcoholic beverages to children. Increasing breast-feeding rates is one of the WHO "best buy" interventions. Six (27\%) of the Member States have legislation/regulations fully implementing the International Code of Marketing of Breast-milk Substitutes. Twelve (55\%) (12/22) of the countries reported the implementation of at least one recent national public awareness and motivational communication for physical activity, including mass media campaigns for physical activity behavioural. These results show a great degree of progress in the areas of nutrition and physical activity since 2015 when no EMR country fully achieved a single one of these indicators (Figure 3).

Finally, in the areas of health care and medication (Figure 3), between 2015 and 2017 the number of EMR countries that have evidence-based national guidelines/ protocols/standards for the management of major NCDs through a primary care approach increased from six to nine. Meanwhile $9(41 \%)$ of the countries have provision of drug therapy, including glycaemic control, and counselling for eligible persons at high risk to prevent heart attacks and strokes, with emphasis on the primary care level in 2017 compared to five countries in 2015. An overall view of these results demonstrates that considerable progress has been made in the Region across a wide range of progress indicators (Figure 4). Certain areas still require much improvement but the continued surveying of these targets will help Member States to focus on these commitments in order to control and prevent NCDs in the Region.

\section{Discussion}

Noncommunicable diseases threaten more than health and are a major challenge for development at global and regional levels. In the 2030 Agenda for Sustainable Development (adopted September 2015), countries recognized NCDs as a leading issue for sustainable development (17). The main responsibility for preventing and controlling NCDs lies with governments and requires that all sectors work together. This was highlighted in the 2011 UN Political Declaration, which called for a wholeof-government and whole-of-society approach to address the global and regional burden of NCDs and their related risk factors (11). In spite of the many declarations of political will to tackle the challenge of NCDs, the limited progress in some areas shows that barriers remain to converting intentions into actions. An honest and open exploration of these obstacles is vital to allow the scaling

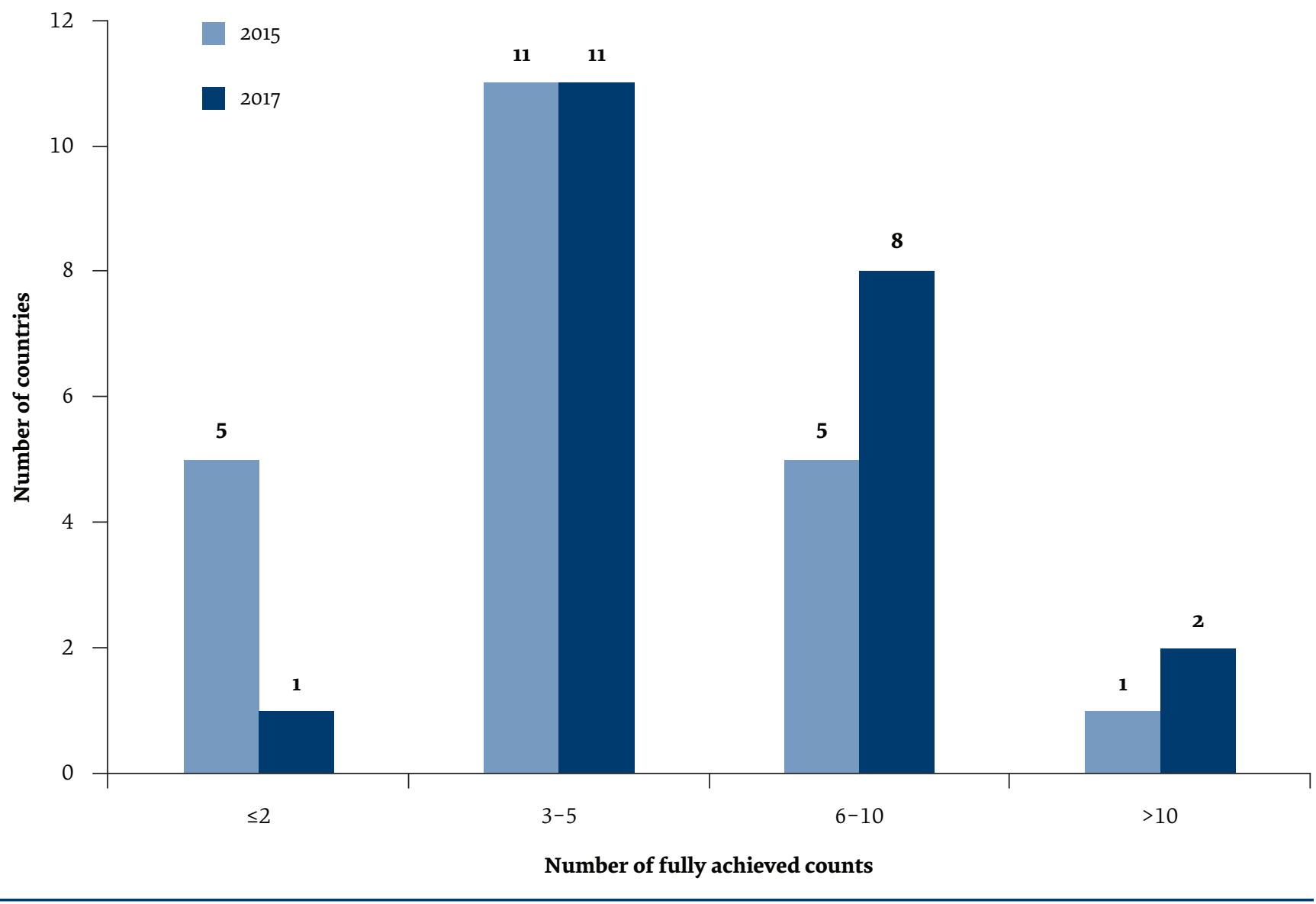

Figure 4 Summary of number of fully achieved indicators 
up of NCD prevention and control in the Region.

Maintaining momentum after the initial political statements is a major challenge that can only be achieved by ensuring the commitment of policy-makers at the highest level of government. These key decision-makers can then ensure the engagement of not only the health sector but also stakeholders from other sectors who can realize the necessary changes. This group includes (but is not limited to) agriculture, communication, education, environment, finance, housing, transport, social/welfare and urban planning. So far, only limited progress has been made in engaging these other areas of government, thus hindering the multisectorial management of NCDs necessary to curb their burden. Another vital player in this arena is the commercial sector, which has the power to make significant changes to their products for health promotion purposes if correctly motivated. Many in the business community have declared, and in some cases demonstrated, the desire to aid public health. However, there is not currently an independent mechanism for assessing the implementation and impact of these commitments.

Enacting NCD control programmes requires a significant financial investment from international, regional and national organizations. The economic case for this action is clear in the long term, but in the short term allocating the necessary funds is a challenge, especially for the many low- and middle-income countries in the Region that are facing a steep increase in the prevalence and burden of NCDs. These countries in particular need, and frequently request, technical assistance from organizations such as WHO to help them develop and re-orientate their health services in an evidence-based manner in order to efficiently combat the full range of NCDs. Investing in the "best buy" interventions recommended by WHO provides a good starting point for these changes.

The EMR countries have stated that they are committed to addressing NCDs (9). The WHO country capacity surveys of 2015 and 2017 show that change is possible, even though more action is still needed for countries to meet their time-bound commitments. Areas requiring specific attention include setting national targets and implementing operational integrated policies/ strategies/action plans, the development of multisectoral action plans; the periodic as well as routine assessment of NCD risk factors; the effective implementation of the "best buys"; and the strengthening of existing regional health care systems' capacities to prevent and control NCDs. WHO is working in close collaboration with countries, using the Regional Framework for Action and the "traffic lights" system, to support them in achieving the outcomes laid out in the UN Political Declaration and 2014 Outcome documents.

\section{The way forward}

Countries of the Region need to renew their commitments and identify those NCD champions that will aggressively push the agenda forward. A sense of urgency must be created with focus placed on four main areas for improvement. NCD prevention and control requires the involvement of multiple stakeholders and therefore multisectoral action plans. Efforts to improve stewardship and advocacy among governments, the private sector, civil society and industry (if collectively and harmoniously working together) will improve progress. Lack of coordination among sectors is costly and ineffective; working together will yield more powerful results.

Innovative solutions in both financing and policy processes are required. Implementing inclusive, integrated approaches coupled with innovative financing mechanisms gather the various NCDs under one strategy as well as supporting new developments at country level. Sound decision-making in NCD prevention and control requires up-to-date and reliable information. Integrating sustainable NCD surveillance systems (that focus on the three pillars of outcome, risk factors and national system response) into national health information systems allows for continuous monitoring and evaluation of countries' progress. Based on the evidence provided by such systems, countries can effectively enforce planning.

Finally, health systems need to be strategically reorientated to integrate NCD management into peoplecentered primary health care. Current health care provision in the Region is often vertically organized into separate disease areas, which do not account for the multiple risk factors and co-morbidities at play in NCDs. The family practice model allows practitioners to develop a holistic view of each patient which enables early detection and management of NCDs. According to the findings of the WHO country capacity surveys, countries need to focus upon stronger leadership and planning in order to tackle the burden of NCDs. The 2011 United Nations Declaration of the High-level Meeting of the General Assembly on the Prevention and Control of NCD represents solid proof that with a strong political will and commitment, change is possible.

Funding: None.

Competing interests: None declared. 


\section{Intensifier la prévention et la maîtrise des maladies non transmissibles dans la Région OMS de la Méditerranée orientale}

\section{Résumé}

La surveillance est une composante essentielle des efforts de prévention et de maitrise des maladies non transmissibles (MNT), tant dans le monde que dans la Région de la Méditerranée orientale. Afin de s'attaquer à la charge croissante de ces maladies, les pays doivent au préalable évaluer leurs propres systèmes et voir quelles mesures doivent être prises pour améliorer la préparation. Par conséquent, le Bureau régional de l'OMS pour la Méditerranée orientale au Caire (Égypte) entreprend régulièrement des enquêtes sur les capacités des pays afin de comparer les dispositions prises par chaque État Membre par rapport au Cadre d'action pour la mise en œuvre de la Déclaration politique des Nations Unies (2011). Dix indicateurs de progrès couvrent la gouvernance et la planification, la réduction des facteurs de risque et la prestation de soins de santé. Chacune de ces catégories se voit attribuer un score permettant de savoir si un pays réalise cet objectif complètement, partiellement ou pas du tout. La présente analyse s'intéresse à la comparaison de rapports de suivi des progrès pour les 22 pays de la Région en 2015 et 2017. Alors que les critères utilisés pour évaluer certains indicateurs ont été mis à jour durant cette période, de nombreuses catégories affichent d'importantes améliorations. Cependant, d'autres catégories nécessitent encore un travail considérable si les pays veulent réaliser l'objectif de développement durable concernant la réduction de $25 \%$ du nombre de décès prématurés dus aux MNT d'ici 2025.

$$
\begin{aligned}
& \text { توسيع نطاق الوقاية من الأمر اض غير السارية والسيطرة عليها في إقليم شرق المتوسط لمنظمة الصحة العالمية }
\end{aligned}
$$

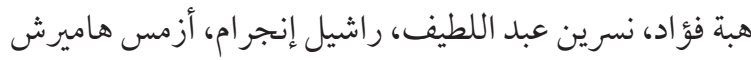

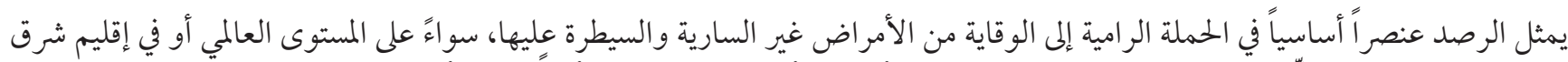

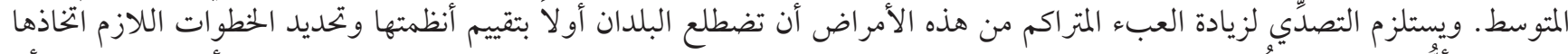

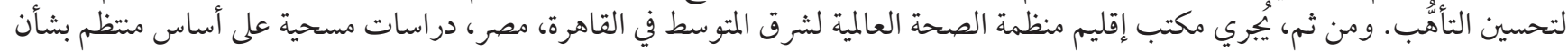

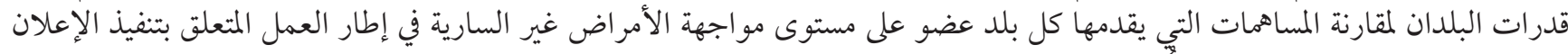

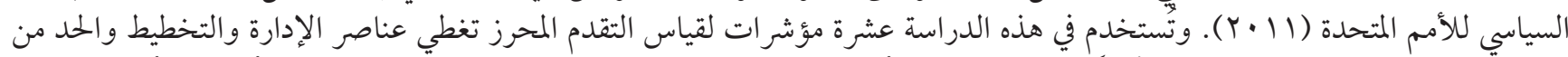

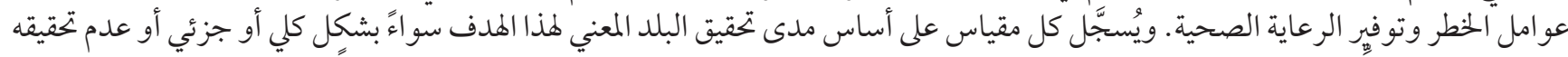

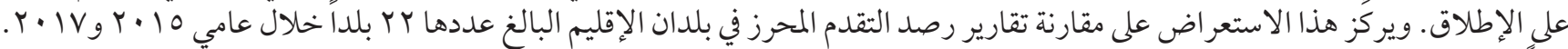

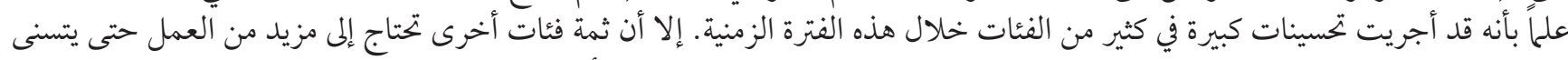

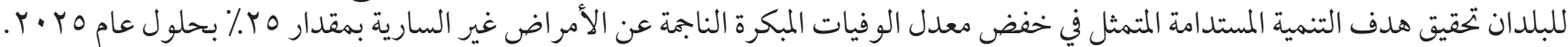

\section{References}

1. Policy briefs and posters: what government ministries need to know about noncommunicable diseases. Geneva: World Health Organization and United Nations Development Programme; 2016 (http://www.who.int/ncds/un-task-force/policy-briefs/en/, accessed 27 August 2017).

2. Noncommunicable diseases: diseases 2017. Cairo: World Health Organization Regional Office for the Eastern Mediterranean; 2017 (http://www. emro.who.int/noncommunicable-diseases/diseases/diseases.html, accessed 27 August 2017).

3. Noncommunicable diseases country profiles 2014. Geneva: World Health Organization; 2014 (http://apps.who.int/iris/bitstre am/9789241507509/1/128038/10665_eng.pdf, accessed 27 August 2017).

4. WHO Global coordination mechanism on the prevention and control of NCDs: NCDs, poverty and development 2017. Geneva: World Health Organization; 2017 (http://www.who.int/global-coordination-mechanism/poverty-and-development/en/, accessed 27 August 2017).

5. Assessing national capacity for the prevention and control of noncommunicable diseases: report of the 2015 country capacity survey in the Eastern Mediterranean Region. Cairo: World Health Organization Regional Office for the Eastern Mediterranean; 2016 (http://applications.emro. who.int/dsaf/EMROPUB_2016_EN_19168.pdf?ua=1, accessed 27 August 2017).

6. Noncommunicable diseases progress monitor, 2015. Geneva: World Health Organization; 2015.

7. Noncommunicable Diseases Progress Monitor, 2017. Geneva: World Health Organization; 2017.

8. United Nations General Assembly Resolution A/RES/2/66. New York: United Nations; 2011.

9. Framework for action to implement the United Nations Political Declaration on Noncommunicable Diseases, including indicators to assess country progress by 2018. Cairo: World Health Organization Regional Office for the Eastern Mediterranean; 2017 (http://applications.emro.who. int/docs/Framework_action_implement_UN_political_declaration_NCD_October_2015_EN.pdf?ua=1, accessed 27 August 2017).

10. Global action plan for the prevention and control of noncommunicable diseases 2013-2020. Geneva: World Health Organization; 2013 (http:// apps.who.int/iris/bitstream/10665/94384/1/9789241506236_eng.pdf?ua=1, accessed 27 August 2017).

11. Noncommunicable diseases and mental health: NCD global monitoring framework 2013. Geneva: World Health Organization; 2017 (http://www. who.int/nmh/global_monitoring_framework/en/, accessed 27 August 2017).

12. Updated Appendix 3 of the WHO Global NCD Action Plan 2013-2020. Geneva: World Health Organisation: 2017 (http://www.who.int/ncds/management/WHO_Appendix_BestBuys_LS.pdf, accessed 20 February 2018). 
13. Global status report on noncommunicable diseases 2014. Geneva: World Health Organization; 2014.

14. United Nations General Assembly Resolution A/RES/300/68. New York: United Nations; 2014.

15. Technical note: how WHO will report in 2017 to the United Nations General Assembly on the progress achieved in the implementation of commitments included in the 2011 UN Political Declaration and 2014 UN Outcome Document on NCDs. Geneva: World Health Organization; 2015 (http://www.who.int/nmh/events/2015/technical-note-en.pdf?ua=1, accessed 27 August 2017)

16. Updated Technical note: how WHO will report in 2017 to the United Nations General Assembly on the progress achieved in the implementation of commitments included in the 2011 UN Political Declaration and 2014 UN Outcome Document on NCDs. Geneva: World Health Organization; 2017 (http://www.who.int/nmh/events/2015/Updated-WHO-Technical-Note-NCD-Progress-Monitor-September2017-.pdf?ua=1, accessed 20 February 2018)

17. Health in 2015: from MDGs, Millennium Development Goals to SDGs, Sustainable Development Goals. Geneva: World Health Organization; 2015 (http://www.who.int/gho/publications/mdgs-sdgs/en/, accessed 16 August 2016).

\section{Supplementary table 1 Full comparison of progress made by countries in prevention and control of NCDs between 2015 and 2017}

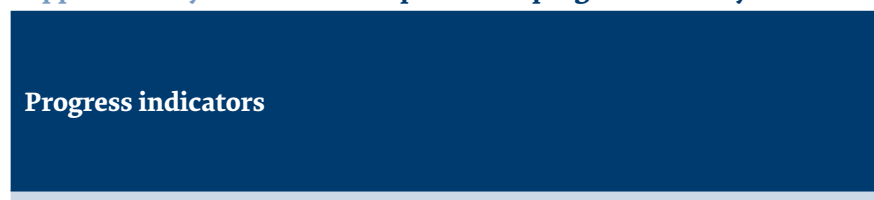

1. Member State has set time-bound national targets based on WHO guidance

2. Member State has a functioning system for generating reliable causespecific mortality data on a routine basis

3. Member State has a STEPS survey or a comprehensive health examination survey every 5 years

4. Member State has an operational multisectoral national strategy/ action plan that integrates the major NCDs and their shared risk factors

5a. Reduce affordability by increasing excise taxes and prices on tobacco products

5b. Eliminate exposure to second-hand tobacco smoke in all indoor workplaces, public places and public transport

5c. Implement plain/standardized packaging and/or large graphic health warnings on all tobacco packages

5d. Enact and enforce comprehensive bans on tobacco advertising, promotion and sponsorship

5e. Implement effective mass media campaigns that educate the public about the harms of smoking/tobacco use and second hand smoke*

6a. Enact and enforce restrictions on the physical availability of retailed alcohol (via reduced hours of sale)

6b. Enact and enforce bans or comprehensive restrictions on exposure to alcohol advertising (across multiple types of media)

6c. Increase excise taxes on alcoholic beverages

7a. Adopted national policies to reduce population salt/sodium consumption

7b. Adopted national policies that limit saturated fatty acids and virtually eliminate industrially produced trans fatty acids in the food supply

7c. WHO set of recommendations on marketing of foods and nonalcoholic beverages to children

7d. Legislation/regulations fully implementing the International Code of Marketing of Breast-milk Substitutes

8. Member State has implemented at least one recent national public awareness and motivational communication for physical activity, including mass media campaigns for physical activity behavioural change

9. Member State has evidence-based national guidelines/protocols/ standards for the management of major NCDs through a primary care approach, recognized/approved

10. Member State has provision of drug therapy, including glycaemic control, and counselling for eligible persons at high risk to prevent heart attacks and strokes, with emphasis on the primary care level

\begin{tabular}{|c|c|c|c|c|c|c|c|c|c|c|c|}
\hline \multicolumn{6}{|c|}{2015} & \multicolumn{6}{|c|}{2017} \\
\hline \multicolumn{2}{|c|}{$\begin{array}{c}\text { Fully } \\
\text { Achieved }\end{array}$} & \multicolumn{2}{|c|}{$\begin{array}{l}\text { Partially } \\
\text { Achieved }\end{array}$} & \multicolumn{2}{|c|}{$\begin{array}{c}\text { Not } \\
\text { Achieved }\end{array}$} & \multicolumn{2}{|c|}{$\begin{array}{c}\text { Fully } \\
\text { Achieved }\end{array}$} & \multicolumn{2}{|c|}{$\begin{array}{l}\text { Partially } \\
\text { Achieved }\end{array}$} & \multicolumn{2}{|c|}{$\begin{array}{c}\text { Not } \\
\text { Achieved }\end{array}$} \\
\hline $\mathbf{N}$ & $\%$ & $\mathbf{N}$ & $\%$ & $\mathbf{N}$ & $\%$ & $\mathrm{~N}$ & $\%$ & $\mathrm{~N}$ & $\%$ & $\mathrm{~N}$ & $\%$ \\
\hline 3 & 14 & 4 & 18 & 14 & 64 & 12 & 55 & 1 & 5 & 9 & 41 \\
\hline 1 & 5 & 12 & 55 & 8 & 36 & 0 & 0 & 14 & 64 & 8 & 36 \\
\hline 2 & 9 & 15 & 68 & 4 & 18 & 3 & 14 & 15 & 68 & 4 & 18 \\
\hline 1 & 5 & 7 & 32 & 13 & 59 & 8 & 36 & 5 & 23 & 9 & 41 \\
\hline 2 & 9 & 4 & 18 & 14 & 64 & 2 & 9 & 8 & 36 & 12 & 55 \\
\hline 6 & 27 & 10 & 45 & 6 & 27 & 6 & 27 & 10 & 45 & 6 & 27 \\
\hline 3 & 14 & 11 & 50 & 8 & 36 & 3 & 14 & 13 & 59 & 6 & 27 \\
\hline 6 & 27 & 13 & 59 & 3 & 14 & 9 & 41 & 12 & 55 & 1 & 5 \\
\hline & & & & & & 3 & 14 & 6 & 30 & 11 & 55 \\
\hline 9 & 41 & 5 & 23 & 0 & 0 & 11 & 50 & 6 & 27 & 0 & 0 \\
\hline 11 & 50 & 3 & 14 & 0 & 0 & 12 & 55 & 2 & 9 & 3 & 14 \\
\hline 7 & 32 & 5 & 23 & 2 & 9 & 9 & 41 & 6 & 27 & 2 & 9 \\
\hline 1 & 5 & 0 & 0 & 7 & 32 & 8 & 36 & 6 & 27 & 8 & 36 \\
\hline 0 & 0 & 0 & 0 & 6 & 27 & 12 & 55 & 0 & 0 & 10 & 45 \\
\hline 0 & 0 & 0 & 0 & 5 & 23 & 7 & 32 & 0 & 0 & 14 & 64 \\
\hline 1 & 5 & 0 & 0 & 8 & 36 & 6 & 27 & 12 & 55 & 3 & 14 \\
\hline 1 & 5 & 0 & 0 & 10 & 45 & 12 & 55 & 0 & 0 & 9 & 41 \\
\hline 6 & 27 & 5 & 23 & 7 & 32 & 9 & 41 & 7 & 32 & 4 & 18 \\
\hline 5 & 23 & 2 & 9 & 11 & 50 & 9 & 41 & 1 & 5 & 12 & 55 \\
\hline
\end{tabular}




\begin{tabular}{|c|c|c|c|c|c|c|c|}
\hline $\begin{array}{l}\text { Progress } \\
\text { indicator } \\
\text { number } \\
\\
\mathbf{1}\end{array}$ & \multirow{2}{*}{$\begin{array}{l}\text { Progress indicator } \\
\begin{array}{l}\text { Member State has set time- } \\
\text { bound national targets } \\
\text { based on WHO guidance }\end{array}\end{array}$} & \multicolumn{2}{|c|}{$\begin{array}{l}\text { Number and } \\
\text { percentage } \\
\text { of countries } \\
\text { partially } \\
\text { achieving } \\
\text { indicator }\end{array}$} & \multirow{2}{*}{$\begin{array}{l}\text { Countries partially } \\
\text { achieving indicator } \\
\text { Jordan }\end{array}$} & \multicolumn{2}{|c|}{$\begin{array}{l}\text { Number and } \\
\text { percentage } \\
\text { of countries } \\
\text { fully achieving } \\
\text { indicator }\end{array}$} & \multirow{2}{*}{$\begin{array}{l}\begin{array}{l}\text { Countries fully achieving } \\
\text { indicator }\end{array} \\
\text { Bahrain-Egypt-Islamic } \\
\text { Republic of Iran-Iraq- Kuwait- } \\
\text { Morocco-Oman-Qatar-Saudi } \\
\text { Arabia-Sudan-United Arab } \\
\text { Emirates-Palestine }\end{array}$} \\
\hline & & 1 & 4.5 & & 12 & 54.5 & \\
\hline 2 & $\begin{array}{l}\text { Member State has a } \\
\text { functioning system for } \\
\text { generating reliable cause- } \\
\text { specific mortality data on a } \\
\text { routine basis }\end{array}$ & 14 & 63.6 & $\begin{array}{l}\text { Bahrain-Egypt-Islamic } \\
\text { Republic of Iran-Iraq-Jordan- } \\
\text { Kuwait-Morocco-Oman- } \\
\text { Qatar-Saudi Arabia-Syrian } \\
\text { Arab Republic-Tunisia- } \\
\text { United Arab Emirates- } \\
\text { Palestine }\end{array}$ & 0 & 0.0 & \\
\hline 3 & $\begin{array}{l}\text { Member State has a STEPS } \\
\text { survey or a comprehensive } \\
\text { health examination survey } \\
\text { every } 5 \text { years }\end{array}$ & 15 & 68.2 & $\begin{array}{l}\text { Afghanistan-Bahrain- } \\
\text { Egypt-Iraq-Jordan- } \\
\text { Kuwait-Lebanon-Libya- } \\
\text { Morocco-Oman-Pakistan- } \\
\text { Qatar-Tunisia-United Arab } \\
\text { Emirates-Palestine }\end{array}$ & 3 & 13.6 & $\begin{array}{l}\text { Islamic Republic of Iran- } \\
\text { Saudi Arabia-Sudan }\end{array}$ \\
\hline 4 & $\begin{array}{l}\text { Member State has an } \\
\text { operational multisectoral } \\
\text { national strategy/action } \\
\text { plan that integrates the } \\
\text { major NCDs and their } \\
\text { shared risk factors }\end{array}$ & 5 & 22.7 & $\begin{array}{l}\text { Egypt-Jordan-Lebanon- } \\
\text { Morocco-Palestine }\end{array}$ & 8 & 36.4 & $\begin{array}{l}\text { Afghanistan-Islamic Republic } \\
\text { of Iran-Kuwait-Saudi Arabia } \\
\text {-Bahrain-Iraq-United Arab } \\
\text { Emirates-Qatar }\end{array}$ \\
\hline \multirow[t]{6}{*}{5} & \multicolumn{7}{|c|}{$\begin{array}{l}\text { Member State has implemented the following four demand-reduction measures of the WHO FCTC at the highest level of } \\
\text { achievement: }\end{array}$} \\
\hline & $\begin{array}{l}\text { a. Reduce affordability by } \\
\text { increasing excise taxes and } \\
\text { prices on tobacco products }\end{array}$ & 8 & 36.4 & $\begin{array}{l}\text { Egypt-Iraq-Morocco- } \\
\text { Pakistan-Sudan- } \\
\text { Syrian Arab Republic } \\
\text { Tunisia-Yemen }\end{array}$ & 2 & 9.1 & Jordan-Palestine \\
\hline & $\begin{array}{l}\text { b. Eliminate exposure to } \\
\text { second-hand tobacco } \\
\text { smoke in all indoor } \\
\text { workplaces, public places } \\
\text { and public transport }\end{array}$ & 10 & 45.5 & $\begin{array}{l}\text { Djibouti-Egypt-Iraq- } \\
\text { Jordan-Kuwait-Morocco- } \\
\text { Saudi Arabia- } \\
\text { Syrian Arab Republic-United } \\
\text { Arab Emirates-Yemen }\end{array}$ & 6 & 27.3 & $\begin{array}{l}\text { Afghanistan-Islamic Republic } \\
\text { of Iran-Lebanon-Libya- } \\
\text { Pakistan-Palestine }\end{array}$ \\
\hline & $\begin{array}{l}\text { c. Implement plain/ } \\
\text { standardized packaging } \\
\text { and/or large graphic health } \\
\text { warnings on all tobacco } \\
\text { packages }\end{array}$ & 13 & 59.1 & $\begin{array}{l}\text { Afghanistan-Bahrain-Iraq- } \\
\text { Jordan-Kuwait-Lebanon- } \\
\text { Oman-Pakistan-Qatar- } \\
\text { Saudi Arabia-Tunisia-United } \\
\text { Arab Emirates-Yemen }\end{array}$ & 3 & 13.6 & $\begin{array}{l}\text { Djibouti-Egypt-Islamic } \\
\text { Republic of Iran }\end{array}$ \\
\hline & $\begin{array}{l}\text { d. Enact and enforce } \\
\text { comprehensive bans } \\
\text { on tobacco advertising, } \\
\text { promotion and sponsorship }\end{array}$ & 12 & 54.5 & $\begin{array}{l}\text { Egypt-Iraq-Jordan } \\
\text { Lebanon-Morocco- } \\
\text { Oman-Pakistan } \\
\text { Saudi Arabia-Sudan- } \\
\text { Syrian Arab Republic-Tunisia- } \\
\text { Palestine }\end{array}$ & 9 & 40.9 & $\begin{array}{l}\text { Afghanistan-Bahrain- } \\
\text { Djibouti-Islamic Republic } \\
\text { of Iran-Kuwait-Libya-Qatar- } \\
\text { United Arab Emirates-Yemen }\end{array}$ \\
\hline & $\begin{array}{l}\text { e. Implement effective mass } \\
\text { media campaigns that } \\
\text { educate the public about } \\
\text { the harms of tobacco use } \\
\text { and second hand smoke }\end{array}$ & 6 & 27.3 & $\begin{array}{l}\text { Bahrain-Islamic Republic } \\
\text { of Iran-Iraq-Saudi Arabia- } \\
\text { Tunisia-United Arab Emirates }\end{array}$ & 3 & 13.6 & Jordan-Morocco-Pakistan \\
\hline 6 & \multicolumn{7}{|c|}{$\begin{array}{l}\text { Member State has implemented, as appropriate according to national circumstances, the following three measures to reduce } \\
\text { the harmful use of alcohol as per the WHO Global Strategy to Reduce the Harmful Use of Alcohol: }\end{array}$} \\
\hline & $\begin{array}{l}\text { a. Enact and enforce } \\
\text { restrictions on the physical } \\
\text { availability of retailed } \\
\text { alcohol (via reduced hours } \\
\text { of sale) }\end{array}$ & 6 & 27.3 & $\begin{array}{l}\text { Djibouti-Jordan- } \\
\text { Lebanon-Morocco- } \\
\text { Pakistan-Palestine }\end{array}$ & 11 & 50.0 & $\begin{array}{l}\text { Afghanistan-Egypt-Iran-Iraq- } \\
\text { Libya-Oman-Saudi Arabia } \\
\text {-Somalia-Sudan-Syrian Arab } \\
\text { Republic-Yemen }\end{array}$ \\
\hline
\end{tabular}


Supplementary table 2 Overall summary of progress indicator achievement in the Eastern Mediterranean Region 2017 (22 countries) (concluded)

\begin{tabular}{|c|c|c|c|c|c|c|c|}
\hline \multirow[t]{3}{*}{$\begin{array}{c}\text { Progress } \\
\text { indicator } \\
\text { number }\end{array}$} & Progress indicator & \multicolumn{2}{|c|}{$\begin{array}{l}\text { Number and } \\
\text { percentage } \\
\text { of countries } \\
\text { partially } \\
\text { achieving } \\
\text { indicator }\end{array}$} & $\begin{array}{l}\text { Countries partially } \\
\text { achieving indicator }\end{array}$ & \multicolumn{2}{|c|}{$\begin{array}{l}\text { Number and } \\
\text { percentage } \\
\text { of countries } \\
\text { fully achieving } \\
\text { indicator }\end{array}$} & $\begin{array}{c}\text { Countries fully achieving } \\
\text { indicator }\end{array}$ \\
\hline & $\begin{array}{l}\text { b. Enact and enforce bans or } \\
\text { comprehensive restrictions } \\
\text { on exposure to alcohol } \\
\text { advertising (across } \\
\text { multiple types of media) }\end{array}$ & 2 & 9.1 & Iraq-Syrian Arab Republic & 12 & 54.5 & $\begin{array}{l}\text { Afghanistan-Djibouti-Egypt- } \\
\text { Iran-Jordan-Libya-Oman- } \\
\text { Pakistan-Saudi Arabia } \\
\text {-Somalia-Sudan-Yemen }\end{array}$ \\
\hline & $\begin{array}{l}\text { c. Increase excise taxes on } \\
\text { alcoholic beverages }\end{array}$ & 6 & 27.3 & $\begin{array}{l}\text { Egypt-Iraq-Jordan-Lebanon- } \\
\text { Oman-Pakistan }\end{array}$ & 9 & 40.9 & $\begin{array}{l}\text { Afghanistan-Djibouti-Iran- } \\
\text { Libya-Saudi Arabia-Somalia- } \\
\text { Sudan-Syrian Arab Republic } \\
\text {-Yemen }\end{array}$ \\
\hline
\end{tabular}

7 Member State has implemented the following four measures to reduce unhealthy diets:

a. Adopted national policies to reduce population salt/ sodium consumption

b. Adopted national policies that limit saturated fatty acids and virtually eliminate industrially produced trans fatty acids in the food supply

c. WHO set of recommendations on marketing of foods and non-alcoholic beverages to children

d. Legislation/regulations fully implementing the International Code of Marketing of Breast-milk Substitutes

8

Member State has implemented at least one recent national public awareness and motivational communication for physical activity, including mass media campaigns for physical activity behavioural change

9

Member State has evidence-based national guidelines/protocols/ standards for the management of major NCDs through a primary care approach, recognized/ approved by government or competent authorities

Member State has provision of drug therapy, including glycaemic control, and counselling for eligible persons at high risk to prevent heart attacks and strokes, with emphasis on the primary care level
6

27.3

Afghanistan-Bahrain

Egypt-Iraq-Kuwait-Qatar

0.0

0.0

12

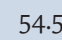

Jibouti-Egypt-Iran-Iraq

Jordan-Oman-Qatar

Saudi Arabia-Sudan-

Syrian Arab Republic-Tunisia-

United Arab Emirates 0.0

7

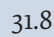

Egypt-Jordan-Morocco-

Pakistan-Syrian Arab

Republic-Tunisia-Palestine
8

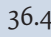

Iran-Jordan-Morocco-OmanSaudi Arabia-Tunisia-United Arab Emirates-Palestine

Afghanistan-Bahrain-IranIraq-Jordan-Kuwait-MoroccoOman-Qatar-Saudi ArabiaTunisia-United Arab Emirates

-Bahrain-IranJordan-Qatar-Saudi ArabiaUnited Arab Emirates

Afghanistan-Bahrain-KuwaitLebanon-Pakistan-Yemen

Bahrain-Iran-Iraq-JordanKuwait-Lebanon-MoroccoOman-Qatar-Saudi ArabiaTunisia-United Arab Emirates
Iran-Iraq-Kuwait-LebanonOman-Qatar-Saudi ArabiaSudan-United Arab Emirates
Bahrain-Iran-Jordan-Kuwait Lebanon-Oman-Saudi Arabia-United Arab EmiratesPalestine 